\title{
Kinetic Study of the Adsorption of Natural Organic Matter From Aqueous Solution by Surfactant Modified Zeolite
}

\author{
Mehdi Vosoughi Niri ${ }^{1, *}$; Amir Hosein Mahvi ${ }^{2,3}$; Mohammad Javad Mohammadi ${ }^{1,4}$; Afshin \\ Takdastan ${ }^{1}$; Amir Zahedi ${ }^{1}$; Bayram Hashemzadeh ${ }^{5}$ \\ 1 Department of Environmental Health Engineering, School of Public Health, Ahvaz Jundishapur University of Medical Sciences, Ahvaz, IR Iran \\ ${ }^{2}$ Department of Environmental Health Engineering, School of Public Health, Tehran University of Medical Sciences, Tehran, IR Iran \\ ${ }^{3}$ National Institute of Health Research, Tehran University of Medical Sciences, Tehran, IR Iran \\ 4 Razi Hospital, Ahvaz Jundishapur University of Medical Sciences, Ahvaz, IR Iran \\ ${ }^{5}$ Department of Environmental Health, Khoy School of Nursing and Public Health, Urumia University of Medical Sciences, Urumia, IR Iran \\ *Corresponding author: Mehdi Vosoughi Niri, Department of Environmental Health Engineering, School of Public Health, Ahvaz Jundishapur University of Medical Sciences, Ahvaz, \\ IR Iran. Tel: +98-9386939465, Fax:+98-6133721675, E-mail: mvn_20@yahoo.com
}

Received: May 10, 2015; Revised: June 7, 2015; Accepted: June 13, 2015

Background: The presence of natural organic matter (NOM) in raw water sources is unfavorable and has long been a problem for water supply industries. Natural zeolite is a low cost material that can be found in nature. Zeolite can be modified and used for removal of NOM from aqueous solutions.

Objectives: In this study, for the first time, the efficiency of modified natural Iranian zeolite obtained from Semnan mines was investigated for removal of NOM from aqueous solution.

Materials and Methods: In this study, batch studies were set up to evaluate the effects of initial pH, contact time and also the initial NOM concentrations on adsorption behavior. The effective initial $\mathrm{pH}$ values were in acidic ranges for adsorption of the NOM by surfactant modified zeolite(SMZ). Kinetic studies showed that the adsorption of NOM by SMZ was a gradual process.

Results: The batch kinetics experiments showed that NOM adsorption by the adsorbents followed the pseudo-second order model. Results showed that the acidic $\mathrm{pH}$ is optimum for adsorption of NOM by SMZ.

Conclusions: The findings of this study show that natural zeolite modified with sodium dodecyl sulfate, as a cationic surfactant, is a promising adsorbent for removal of NOM.

Keywords: Natural Organic Matter; Adsorption Kinetics; Zeolites; Sodium Dodecyl Sulfate

\section{Background}

Humic compounds are considered the most portion of natural organic matter (NOM) found in many surface water sources (1-3). Natural organic matter is one of the main components of organic matter, which form the major portion of dissolved organic materials. The NOM components are an anionic molecule with surface functional groups as carboxylic and phenolic groups $(2,4,5)$. High concentrations of NOM may cause harmful compounds in treated drinking water. The presence of NOM in raw water sources is unfavorable and has long been a problem for water supply system industries. Particularly, NOM affects the quality of drinking water in several points. Color is an important esthetic drinking water quality $(6,7)$. In addition, NOM can bind synthetic organic pollutants (such as pesticides) and heavy metals and result in transport of them through the treatment units and distribution network (5, 8-10). Also, as a matter of the presence of high concentrations of NOM in raw water, chlorination of raw water can result in disinfection by-products (DBPs) such as trihalomethanes (THMs) during the chlorination process $(1,5,8)$. Therefore, the removal of NOM from drinking water resources is so important. There are various methods for removal of NOM from raw water such as membrane processes (nanofilters and reverse osmosis), chemical coagulation and precipitation, advanced oxidation, and adsorption (9-13). Among the above-mentioned processes, adsorption is the most applicable and acceptable method. Many different adsorbents including activated carbon, resin, unburned carbon, chitosan, and surfactant modified bentonite have been applied for synthetic humic acid removal $(8,14-16)$. In recent years, also the natural zeolite has been studied for removal of various pollutants from water and wastewater. Natural zeolites are hydrated aluminosilicates with structure by tetrahedrons silicon tetraoxide $\left(\mathrm{SiO}_{4}\right)$ and tetra oxide aluminum $\left(\mathrm{AlO}_{4}\right)$ including water molecules, alkali and alkaline earth metals in their structures $(1,17)$. In this regard, natural zeolites generally can exchange cations instead of anions, which making them appropriate for surface modification by cationic surfactant $(3,8)$. Cation-

Copyright @ 2015, Ahvaz Jundishapur University of Medical Sciences. This is an open-access article distributed under the terms of the Creative Commons Attribution-NonCommercial 4.0 International License (http://creativecommons.org/licenses/by-nc/4.0/) which permits copy and redistribute the material just in noncommercial usages, provided the original work is properly cited. 
Vosoughi Niri M et al.

ic surfactant comprising the positive groups can readily exchange its group with the exchangeable cations on the external surface of zeolite, which results in improving the adsorption capacity $(1,18-21)$. To our knowledge, no studies have been examined in relation to NOM sorption on modified zeolite by Sodium Dodecyl Sulfate (SDS). It should be mentioned that zeolites from different sources have different characteristics, which can affect their adsorption potential for different types of zeolite.

\section{Objectives}

In this study, the efficiency of modified natural Iranian zeolite obtained from Semnan mines for the first time was investigated for removal of NOM from aqueous solution.

\section{Materials and Methods}

\subsection{Materials}

The natural zeolite was purchased from Afrazand Co. Ltd. The surface morphology of the zeolite was analyzed using the scanning electron microscopy technique (XL30Philips Holland). X-ray fractionation (XRF) (PW 2404 Philips Holland) and X-ray diffraction (XRD) (PhilipsXPERT) techniques were used to analyze the chemical composition and the crystallinity phase of the zeolite samples, respectively. The NOM sodium salt was obtained from Sigma-Aldrich Company. Sodium dodecyl sulfate was purchased from Merck Company, Germany. The NOM solution samples were real and collected from Tehran Latiyan dam. Other chemicals used in this study were obtained from Merck Company, Germany.

\subsection{Preparation of Adsorbent}

The zeolite tuff was ground and sieved by $0.21-0.3 \mathrm{~mm}$ American society for testing and materials (ASTM) sieves. The milled zeolitic tuff was washed for several times to remove inorganic impurities; then, for dissolution of salts, the zeolite tuff was completely soaked in deionized water for 24 hours. To eliminate organic materials in the zeolite, it was then dried at temperature above $250^{\circ} \mathrm{C}$ in an oven for 24 hours $(22,23)$.

\subsection{Cationic Form of Zeolite}

Before the modification of the zeolite surface with the surfactant, in order to make monotonous adsorption sites on the zeolite surface with sodium, $10 \mathrm{~g}$ of the zeolite was added to each conical flask containing $100 \mathrm{~mL}$ sodium chloride solution of 2 Molar concentration. Then the conical flasks were shaken by an incubator shaker $\left(150 \mathrm{rpm} ; 20^{\circ} \mathrm{C}\right)$ for 24 hours $(22,24)$. To prevent the possible intervention of the chloride anions in the modification of the zeolite, samples were washed several times with distilled water to remove the remaining chloride. The residual chloride in the supernatant of the premodi- fied samples was determined by silver nitrate $\left(\mathrm{AgNO}_{3}\right)$ using the argentometry method (25). Finally, the samples were dried in oven at $50^{\circ} \mathrm{C}$ for 24 hours (17).

\subsection{Surfactant Modification of Zeolite}

The zeolite surfactant modification can improve the adsorption capacity. A monolayer will be formed when the surfactant concentration is equal or less than its critical micelle concentration (CMC). The surfactant molecules will form a bilayer of surfactant on the surface of the zeolite if the surfactant concentration in a solution exceeds the CMC (26). The surfactant modification of the zeolite makes a hydrophobic environmental conditions for the partitioning of the organic molecules with low polarity and high molecular weight (27). The critical micelle concentration of SDS is $1.8 \mathrm{mmol} / \mathrm{L}(22,24)$. In order to determine the effect of surfactant concentration on adsorption of NOM, three initial concentrations of SDS surfactant (0.5, 1.8 and $20 \mathrm{mmol} / \mathrm{L})$ were selected which are in lesser, equal and higher concentrations than the CMC of the surfactant for modification. For preparation of modified zeolite, $10 \mathrm{~g}$ of prepared cationic zeolite were put into a $200 \mathrm{~mL}$ conical flask containing $100 \mathrm{~mL}$ of different concentration of SDS (0.5, 1.8 and $20 \mathrm{mmol} / \mathrm{L})$. Then the flasks were shaken in an incubator shaker $\left(20^{\circ} \mathrm{C}\right.$, $150 \mathrm{rpm}$ ) for 24 hours. The solid was washed with distilled water repeatedly until no bromine $\left(\mathrm{Br}^{-}\right)$was detected by $\mathrm{AgNO}_{3}$ solution, and then it was dried in an oven at $50^{\circ} \mathrm{C}$ for 24 hours $(22,24)$. The zeolite modified with $0.5,1.8$ and $20 \mathrm{mmol} / \mathrm{L}$ of SDS solutions were named as SMZ1, SMZ2 and SMZ3, respectively.

\subsection{Adsorption Experiments}

To compare the efficiencies of NOM removal with different types of modified adsorbents, $100 \mathrm{~mL}$ of constant concentration of NOM was poured into a conical flask, and then a fixed dose $(0.08 \mathrm{~g} / \mathrm{L})$ of different adsorbents was added to each flask. The solutions were shaken at the equilibrium time. The removal percentage of NOM was calculated by using Equation 1. The adsorbent with higher adsorption toward NOM was chosen for using in the next experiments. All the adsorption experiments were carried out in a batch system. A stock solution of $1000 \mathrm{mg} / \mathrm{L}$ of NOM was prepared by dissolving special amounts of NOM in distilled water. This solution was diluted to obtain the required solutions. The Kinetics of the adsorption were determined by analyzing the adsorption of the NOM at different time intervals. Total organic carbon (TOC) analyzer (TOC-VCSH, Shimadzu, Japan) was used to analyze NOM in the aqueous solutions. The effect of different doses of the adsorbent, which were ranging from $0.2 \mathrm{~g} / \mathrm{L}$ to $1.2 \mathrm{~g} / \mathrm{L}$ was examined. The influence of initial $\mathrm{pH}$ was studied in various ranges (3 - 11). Also, 0.1 normal hydrochloric acid $(\mathrm{HCl})$ and sodium hydroxide $(\mathrm{NaOH})$ prepared from the analytic grade chemicals were 
used for the $\mathrm{pH}$ adjustment. The removal percentage of NOM was calculated using the Equation 1.

\section{(1) \%Removal of $\mathrm{NOM}=\left[\frac{C_{0}-C_{t}}{C_{0}}\right] \times 100$}

Where $C_{0}$ and $C_{t}$ are the initial and residual concentrations of $\mathrm{NOM}(\mathrm{mg} / \mathrm{L})$, respectively.

Blank samples were used as control for each series of the experiments. The amount of adsorbed NOM on SMZ was calculated using Equation 2.

$$
q_{e}=\left[\frac{C_{o}-C_{e}}{M}\right] \times V
$$

Where $\mathrm{C}_{0}$ and $\mathrm{C}_{\mathrm{e}}$ are the initial and equilibrium liquidphase concentrations of NOM, respectively $(\mathrm{mg} / \mathrm{L}), \mathrm{V}$ is the volume of the solution (L), and $\mathrm{M}$ is the weight of the used adsorbent (g) (20).

\section{Results}

The XRD pattern showed that clinoptilolite was the main component of the zeolitic tuff. The surface of the natural zeolite was observed using a scanning electron microscope (SEM) device. The chemical compositions of the zeolite are given in Table 1. The cation exchange capacity and external cation exchange capacity of the natu- ral zeolite were determined to be 1.85 meq/g and 0.205 $\mathrm{meq} / \mathrm{g}$, respectively.

\subsection{Effect of Different Types of the Modified Zeolite}

According to the results, the SMZ3 as the zeolite loaded with a surfactant concentration greater than CMC has higher capacity to adsorb NOM; therefore, among the other types of the adsorbents, SMZ3 was chosen as the best adsorbent and used for the next experiments.

\subsection{Contact Time and Initial Concentration}

Figure 1 illustrates the effect of contact time and initial concentration on the adsorption of NOM by SMZ3. To assess the effect of contact time and initial concentration of NOM, a fixed dose of SMZ3 at $\mathrm{pH}=7$ was used for each concentration of NOM.

\subsection{Effect of $\mathrm{pH}$}

Figure 2 shows that the NOM removal efficiency increases with decreasing the $\mathrm{pH}$ values. The acidic $\mathrm{pH}$ was found to be an optimum pH for NOM adsorption onto SMZ3.

\subsection{Adsorption Kinetics}

The pseudo-first order of Lagergren is one of the most widely used equations for sorption of solute from a liquid solution $(28,29)$. The differential pseudo-first order equation is as follows (Equation 3).

Table 1. Chemical Composition of Natural Zeolite ${ }^{a}$

\begin{tabular}{|c|c|c|c|c|c|c|c|c|c|c|c|c|c|}
\hline Component & $\mathrm{SiO}_{2}$ & $\mathrm{Al}_{3} \mathbf{O}_{2}$ & $\mathrm{Na}_{2} \mathrm{O}$ & MgO & $\mathbf{P}_{5} \mathbf{O}_{2}$ & $\mathrm{SO}_{3}$ & $\mathbf{K}_{2} \mathbf{O}$ & $\mathrm{CaO}$ & $\mathrm{TiO}_{2}$ & $\mathrm{Fe}_{2} \mathrm{O}_{3}$ & $\mathrm{Sr}$ & $\mathrm{Zr}$ & $\begin{array}{l}\text { Loss by } \\
\text { Ignition }\end{array}$ \\
\hline $\mathbf{W} / \mathbf{w}, \%$ & 69.321 & 10.475 & 2.224 & 0.41 & 0.02 & 0.045 & 4.028 & 1.289 & 0.191 & 0.662 & 0.028 & 11.27 & 0.017 \\
\hline
\end{tabular}

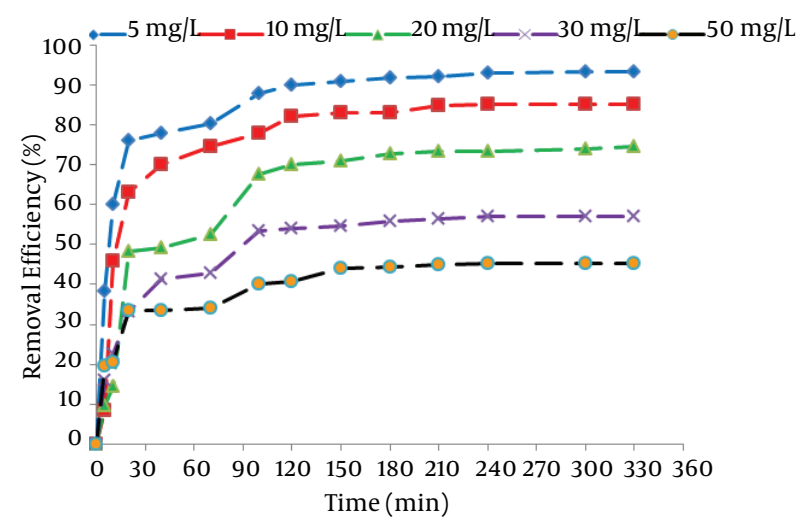

Figure 1. Effect of Contact Time and Initial Concentration on Natural Organic Matter (NOM) Removal Efficiency $(\mathrm{pH}=7$, Adsorbent Dose $=0.8 \mathrm{~g} / \mathrm{L}$ )

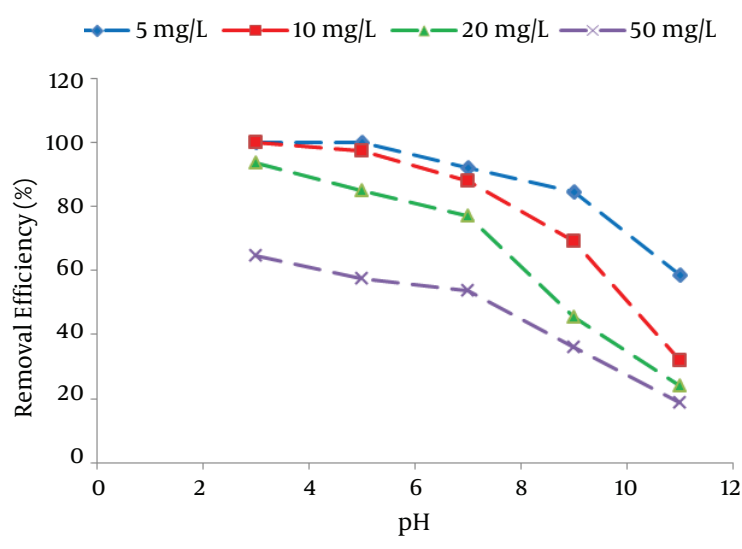

Figure 2. Effect of $\mathrm{pH}$ on Natural Organic Matter (NOM) Removal Efficiency (Adsorbent Dose $=0.8 \mathrm{~g} / \mathrm{L}, \mathrm{t}=300$ minutes) 


$$
\frac{d p_{t}}{d_{t}}=K_{1}\left(q_{e}-q_{t}\right)
$$

Where $\mathrm{q}_{\mathrm{t}}$ and $\mathrm{q}_{\mathrm{e}}$ are the amounts of the NOM adsorbed ( $\mathrm{mg} / \mathrm{g}$ ) at time $t$ and at equilibrium time, respectively and $\mathrm{k}_{1}$ is the rate constant of adsorption $\left(\mathrm{min}^{-1}\right)$. The integration of Equation 3 with the initial condition, $\mathrm{q}_{\mathrm{t}}=0$ at $\mathrm{t}=0$ leads to Equation 4:

$$
\text { (4) } \log \left(q_{e}-q_{t}\right)=\log q-\left(\frac{K_{1}}{2.303}\right) \times t
$$

Ho's pseudo-second order kinetic model: The differential equation is expressed as Equation 5 (18). Figure 3 shows the plot of lined form of pseudo-first order kinetic at all concentrations of NOM.

$$
\frac{d p_{t}}{d_{t}}=K_{2}\left(q_{e}-q_{t}\right)_{2}
$$

Where $\mathrm{K}_{2}$ is the equilibrium rate constant calculated for the pseudo-second order adsorption model $\left(\mathrm{gmg}^{-1} \mathrm{~min}^{-1}\right)$. Integrating Equation 5 for the boundary condition $\mathrm{q}_{\mathrm{t}}=0$ to $\mathrm{q}_{\mathrm{t}}$ at $\mathrm{t}=0$ to $\mathrm{t}$, gives Equation 6 :

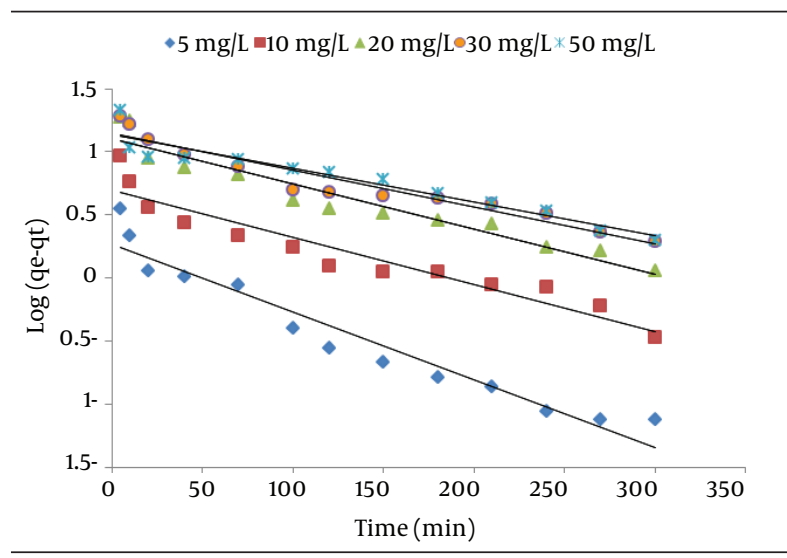

Figure 3. Pseudo-First Order Kinetics for Natural Organic Matter (NOM) Adsorption by Surfactant Modified Zeolite 3 (SMZ3) (Adsorbent Dose $=0.8$ $\underline{\mathrm{g} / \mathrm{L}, \mathrm{pH}=7 \text { ) }}$

$$
\frac{1}{q_{e}-q_{t}}=\frac{1}{q_{e}+K_{2}}
$$

Where $\mathrm{h}$ is the initial sorption rate, which can be obtained from the intercept, $\mathrm{K}_{2}$ is the equilibrium rate constant calculated for the pseudo-second order adsorption model $\left(\mathrm{g} \mathrm{mg}^{-1} \mathrm{~min}^{-1}\right)$

\section{Discussion}

\subsection{Effect of Contact Time and Initial Concentration}

The experiments showed that the removal efficiency of
NOM on the zeolite surface increased gradually, by increasing of the contact time. The adsorption of $\mathrm{AH}$ was faster in initial stages then became slow and finally reached to equilibrium at approximately 150 minutes. Figure 1 represents that the removal efficiency of NOM depends on the initial concentration of $\mathrm{AH}$ in the solution. At the equilibrium time, by increasing the initial concentration of NOM from 5 to $50 \mathrm{mg} / \mathrm{L}$, the removal efficiency increased from $40 \%$ to 93\%. It was observed that the removal efficiency of NOM was increased with the increase in the contact time for all initial NOM concentrations. These observations show that initial NOM concentration has no effect on required time for equilibrium. During the initial stages, many numbers of vacant sites are accessible on the surface of the adsorbent; therefore, the adsorption rate of NOM is relatively high. The adsorption process becomes less efficient due to the gradual occupancy of these sites. With increasing the time, the occupation of the remaining vacant sites due to increased repulsive forces between NOM and bulk solution is more difficult. These results are consistent with the other similar studies $(8,30)$.

\subsection{Effect of $p H$}

According to literature, electrostatic interaction may be significant mechanisms for NOM adsorption onto SDS modified zeolite with bilayer coverage, in addition to hydrophobic interaction and hydrogen bonding $(18,30)$. Since the surface charge of SDS modified zeolite with bilayer coverage is positive, this will favor the adsorption of negative charge ions of NOM (18). HA, fulvic acid, and tannic acid are the principal components of NOM, and are anionic hydrophobic macromolecules and have functional groups comprising the weakly acidic functional groups. At lower $\mathrm{pH}$ states, most of the weakly acidic functional groups uncharged conditions; and therefore, more adsorbable by $\operatorname{SMZ}(30,31)$. Also, the increase of solution $\mathrm{pH}$ leads to the increase of the competitions between the hydroxyl ion and the ionized NOM molecule for the same positively charged adsorption sites on the surface of SMZ3, which causes a decreased NOM adsorption capacity $(15,18)$. In addition, it is noticeable that NOM molecular size may increase from a spherical structure form at low $\mathrm{pH}$ to a linear structure form at high $\mathrm{pH}$, which also indicates the reduction of NOM adsorption at increased $\mathrm{pH}$ values $(15,17)$. Many studies have reported the similar results for other adsorbents (32-34). The aim of this study was to use the acquired experimental data for application in the water treatment where the $\mathrm{pH}$ of the water is in the range of 5 - 7. Therefore, we decided to use these $\mathrm{pH}$ ranges in our experiments.

\subsection{Kinetics}

The pseudo-first order model: the intercept and slope of Figure 3 were used to determine the values of equilibrium adsorption capacity $\mathrm{q}_{\mathrm{e}}$ and pseudo-first order rate constant $k_{1}$, respectively $(29,35)$. The calculated rate constant, experimental and calculated $\mathrm{q}_{\mathrm{e}}$ and corresponding correlation coefficient values were presented in Table 2 . It was 
Vosoughi Niri M et al.

Table 2. Pseudo-First and Pseudo-Second Order Adsorption Rate Constants and the Calculated and Experimental $\mathrm{Q}_{\mathrm{e}}$ for Adsorption of Natural Organic Carbon (NOM) onto Surfactant Modified Zeolite 3 (SMZ3)

\begin{tabular}{|c|c|c|c|c|c|c|c|}
\hline \multirow{2}{*}{$\begin{array}{l}\text { Kinetic Models } \\
\text { Concentration }\end{array}$} & \multirow{2}{*}{$\begin{array}{l}\text { Experimental } \\
\mathrm{q}_{\mathrm{e}}(\exp )(\mathrm{mg} / \mathrm{L}) \\
\end{array}$} & \multicolumn{3}{|c|}{ Pseudo First Order } & \multicolumn{3}{|c|}{ Pseudo Second Order } \\
\hline & & $\mathrm{K}_{1}\left(\mathrm{~min}^{-1}\right)$ & $\mathrm{q}_{\mathrm{e}}(\mathrm{mg} / \mathrm{g})$ & $r^{2}$ & $\mathrm{~K}_{2}\left(\mathrm{~g} \mathrm{mg}^{-1} \mathrm{~min}^{-1}\right)$ & $\mathrm{q}_{\mathrm{e}}(\mathrm{mg} / \mathrm{g})$ & $\mathrm{r}^{2}$ \\
\hline $5 \mathrm{mg} / \mathrm{L}$ & 5 & 0.011515 & 1.86 & 0.935 & 0.06959 & 5.9 & 0.993 \\
\hline $10 \mathrm{mg} / \mathrm{L}$ & 11.45 & 0.006909 & 5 & 0.905 & 0.0059 & 11.5 & 0.998 \\
\hline $20 \mathrm{mg} / \mathrm{L}$ & 22 & 0.006909 & 12.7 & 0.926 & 0.0013 & 21 & 0.993 \\
\hline $30 \mathrm{mg} / \mathrm{L}$ & 24.3 & 0.006909 & 14 & 0.924 & 0.0019 & 23.5 & 0.997 \\
\hline $50 \mathrm{mg} / \mathrm{L}$ & 32 & 0.004606 & 13.5 & 0.916 & 0.0022 & 31.6 & 0.994 \\
\hline
\end{tabular}

also observed that correlation coefficients $\left(\mathrm{r}^{2}\right)$ were relatively low for all NOM concentrations. The calculated $\mathrm{q}_{\mathrm{e}}$ values for pseudo-first order kinetic did not agree with experimental values very well (Table 2 ). These results showed no applicability of the pseudo-first order model in foretelling the kinetics of NOM adsorption onto the SMZ3.

The pseudo-first order model: Equation 6 can be arranged to obtain linear form (Equations 7 and 8)

$$
\frac{t}{q}=\frac{1}{K_{2} q_{e}^{2}}+\frac{1}{q_{e}} \times t
$$

$$
h=K_{2} q_{e}^{2}
$$

The $\mathrm{q}_{\mathrm{e}}$ is obtained from the slope of the plot of $\mathrm{t} / \mathrm{q}_{\mathrm{t}}$ against $t$ (Figure 4), K2 can be calculated from the value of the initial sorption rate. The calculated $\mathrm{q}_{\mathrm{e}}$ values agreed very well with the experimental data (Table 2 ). The correlation coefficients $\left(\mathrm{r}^{2}\right)$ for the pseudo-second order kinetic model were higher than 0.99 for all concentrations. These indicated that the adsorption of NOM from solution onto SMZ3 obeys the pseudo-second order kinetic model. Same results were observed in other studies (18).

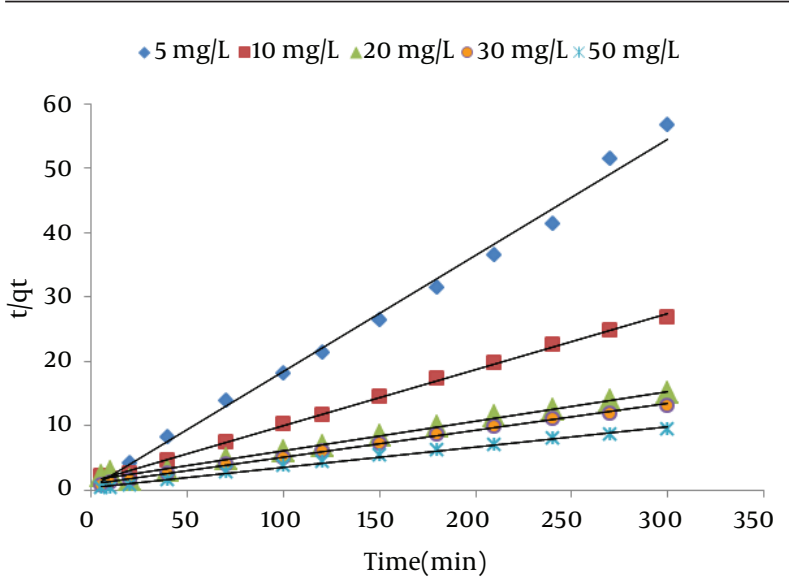

Figure 4. Pseudo-Second Order Kinetics for Natural Organic Matter (NOM) Adsorption onto Surfactant Modified Zeolite 3 (SMZ3) (Adsorbent Dose $=0.8 \mathrm{~g} / \mathrm{L}, \mathrm{pH}=7$ )
The results showed that SMZ can be used as low-cost adsorbent for adsorption of NOM from aqueous solution. Adsorption of NOM by SMZ was enhanced at acidic $\mathrm{pH}$ levels. For SMZ with SDS bilayer coverage, the NOM adsorption process followed reasonably well a pseudo-second order kinetic model. Results from this study indicate that the SDS-modified natural zeolite with surfactant bilayer coverage is a favorable adsorbent for the removal of NOM from aqueous solutions. It is better to mention that some limitations in preparing SMZ may be rise up such as foam making during treating. This research was carried out in lab scale, while it should be done in real water treatment plants. In this study, the authors didn't study the recovery of SMZ but the thermal regeneration was considered as a probable approach.

\section{Acknowledgements}

The author would like to appreciate the support of Ahvaz Jundishapur University of Medical Sciences.

\section{Authors' Contributions}

Study concept, design, and critical revision of the manuscript for important intellectual content: Mehdi Vosoughi Niri, Amir Hosein Mahvi, Mohammad Javad Mohammadi, Afshin Takdastana, Amir Zahedi, and Bayram Hashemzadeh. Drafting of the manuscript and advisor: Mehdi Vosoughi Niri. Conducting experiments: Mohammad Javad Mohammadi.

\section{Funding/Support}

This study was financially supported by Ahvaz Jundishapur University of Medical Sciences, Ahvaz, IR Iran.

\section{References}

1. Wang S, Gong W, Liu X, Gao B, Yue Q. Removal of fulvic acids using the surfactant modified zeolite in a fixed-bed reactor. Separat Purificat Technol. 2006;51(3):367-73.

2. Brigante M, Zanini G, Avena M. On the dissolution kinetics of humic acid particles. Effect of monocarboxylic acids. Chemosphere. 2008;71(11):2076-81.

3. Zazouli MA, Nasseri S, Mahvi AH, Mesdaghinia AR, Younecian M Gholami M. Determination of Hydrophobic and Hydrophilic Fractions of Natural Organic Matter in Raw Water of Jalalieh and Tehranspars Water Treatment Plants (Tehran). J Appl Sci. 2007;7(18):2651-5.

4. Brigante M, Zanini G, Avena M. Effect of $\mathrm{pH}$, anions and cations 
on the dissolution kinetics of humic acid particles. Colloids Surfaces Physicochem Engin Aspects. 2009;347(1-3):180-6.

5. Zazouli MA, Nasseri S, Mahvi AH, Gholami M, Mesdaghinia AR, Younesian M. Retention of humic acid from water by nanofiltration membrane and influence of solution chemistry on membrane performance. Iran J Environ Health Sci Engin. 2008;5(1):11-8.

6. Bazrafshan E, Biglari H, Mahvi AH. Humic acid removal from aqueous environments by electrocoagulation process using iron electrodes.J Chem. 2012;9(4):2453-61.

7. Li C, Dong Y, Wu D, Peng L, Kong H. Surfactant modified zeolite as adsorbent for removal of humic acid from water. Appl Clay Sci. 2011;52(4):353-7.

8. Anirudhan T, Ramachandran M. Surfactant-modified bentonite as adsorbent for the removal of humic acid from wastewaters. Appl Clay Sci. 2007;35(3-4):276-81.

9. Imyim A, Prapalimrungsi E. Humic acids removal from water by aminopropyl functionalized rice husk ash. J Hazard Mater. 2010;184(1-3):775-81.

10. Mahvi AH, Maleki A, Rezaee R, Safari M. Reduction of humic substances in water by application of ultrasound waves and ultraviolet irradiation. Iranian Association of Environmental Health (IAEH); 2010.

11. Chiang PC, Chang EE, Chang PC, Huang CP. Effects of pre-ozonation on the removal of THM precursors by coagulation. Sci Total Environ. 2009;407(21):5735-42.

12. Christl I, Kretzschmar R. C-1s NEXAFS spectroscopy reveals chemical fractionation of humic acid by cation-induced coagulation. Environ Sci Technol. 2007;41(6):1915-20.

13. Landrum PF, Nihart SR, Eadie BJ, Gardner WS. Reverse-phase separation method for determining pollutant binding to Aldrich humic acid and dissolved organic carbon of natural waters. Environ Sci Technol. 1984;18(3):187-92.

14. Chen JP, Wu S. Simultaneous adsorption of copper ions and humic acid onto an activated carbon. J Colloid Interface Sci. 2004;280(2):334-42.

15. Wang $\mathrm{S}$, Zhu ZH. Humic acid adsorption on fly ash and its derived unburned carbon. J Colloid Interface Sci. 2007;315(1):41-6.

16. Wan Ngah WS, Hanafiah MA, Yong SS. Adsorption of humic acid from aqueous solutions on crosslinked chitosan-epichlorohydrin beads: kinetics and isotherm studies. Colloids SurfB Biointerfaces. 2008;65(1):18-24.

17. Lin J, Zhan Y, Zhu Z, Xing Y. Adsorption of tannic acid from aqueous solution onto surfactant-modified zeolite.J Hazardous Mater. 2011;193:102-11.

18. Zhan Y, Zhu Z, Lin J, Qiu Y, Zhao J. Removal of humic acid from aqueous solution by cetylpyridinium bromide modified zeolite. JEnvironl Sci. 2010;22(9):1327-34.

19. Vosoughi Niri M, Shirmardi M, Asadi A, Golestani H, Naeimabad A, Mohammadi MJ, et al. Erratum to: "Reactive red 120 dye removal from aqueous solution by adsorption on nano-alumina".J Water Chem Technol. 2014;36(4):203.

20. Shirmardi M, Mahvi AH, Hashemzadeh B, Naeimabadi A, Hassani
G, Niri MV. The adsorption of malachite green (MG) as a cationic dye onto functionalized multi walled carbon nanotubes. Korean JChem Engin. 2013;30(8):1603-8.

21. Nadafi K, Vosoughi M, Asadi A, Borna MO, Shirmardi M. Reactive Red 120 dye removal from aqueous solution by adsorption on nano-alumina.J Water Chem Technol. 2014;36(3):125-33.

22. Ghadiri SK, Nabizadeh R, Mahvi AH, Nasseri S, Kazemian H, Mesdaghinia AR, et al. Methyl tert-butyl ether adsorption on surfactant modified natural zeolites. Iran J Environ Health Sci Engin. 2010;7(3):241-52.

23. Koh S, Dixon JB. Preparation and application of organo-minerals as sorbents of phenol, benzene and toluene. Appl Clay Sci. 2001;18(3-4):111-22.

24. Torabian A, Kazemian H, Seifi L, Bidhendi GN, Azimi A, Ghadiri SK. Removal of Petroleum Aromatic Hydrocarbons by Surfactantmodified Natural Zeolite: The Effect of Surfactant. CLEAN Soil Air Water. 2010;38(1):77-83.

25. Ghiaci M, Abbaspur A, Kia R, Seyedeyn-Azad F. Equilibrium isotherm studies for the sorption of benzene, toluene, and phenol onto organo-zeolites and as-synthesized MCM-41. Separat Purif Technology. 2004;40(3):217-29.

26. Haggerty GM, Bowman RS. Sorption of chromate and other inorganic anions by organo-zeolite. Environ Sci Technol. 1994;28(3):452-8.

27. Wang S, Peng Y. Natural zeolites as effective adsorbents in water and wastewater treatment. Chem Engin J. 2010;156(1):11-24.

28. Ghaedi M, Tashkhourian J, Pebdani AA, Sadeghian B, Ana FN. Equilibrium, kinetic and thermodynamic study of removal of reactive orange 12 on platinum nanoparticle loaded on activated carbon as novel adsorbent. Korea J Chem Engin. 2011;28(12):2255-61.

29. Hartono T, Wang S, Ma Q, Zhu Z. Layer structured graphite oxide as a novel adsorbent for humic acid removal from aqueous solution.J Colloid Interface Sci. 2009;333(1):114-9.

30. Zhan Y, Lin J, Qiu Y, Gao N, Zhu Z. Adsorption of humic acid from aqueous solution on bilayer hexadecyltrimethyl ammonium bromide-modified zeolite. Frontiers Environ Sci Engin China. 2011;5(1):65-75.

31. Moussavi G, Talebi S, Farrokhi M, Sabouti RM. The investigation of mechanism, kinetic and isotherm of ammonia and humic acid co-adsorption onto natural zeolite. Chem Engin J. 2011;171(3):1159-69.

32. Amin NK. Removal of reactive dye from aqueous solutions by adsorption onto activated carbons prepared from sugarcane bagasse pith. Desalination. 2008;223(1-3):152-61.

33. Monash P, Pugazhenthi G. Investigation of equilibrium and kinetic parameters of methylene blue adsorption onto MCM-41. Korea J Chem Engin. 2010;27(4):1184-91.

34. Wang J, Ding S, Zheng C, Ma H, Ji Y. Efficient removal of humic acid in aqueous solution using polyaniline adsorbent. Desalinat WaterTreatment. 2012;40(1-3):92-9.

35. Ho YS, McKay G. Pseudo-second order model for sorption processes. Process Biochem. 1999;34(5):451-65. 